\title{
Terraform Sustainability Assessment Framework for Bioregenerative Life Support Systems
}

\author{
Morgan A. Irons ${ }^{1 *}$ and Lee G. Irons ${ }^{2}$ \\ ${ }^{1}$ School of Integrative Plant Science, Field of Soil and Crop Sciences, Cornell University, Ithaca, NY, United States, ${ }^{2}$ Norfolk \\ Institute LLC, Norfolk, VA, United States
}

\section{OPEN ACCESS}

Edited by: Cyprien Verseux

University of Bremen, Germany

Reviewed by: Kazuharu Bamba,

Fukushima University, Japan Milan S. Dimitrijevic, Astronomical Observatory, Serbia

*Correspondence:

Morgan A. Irons mai57@cornell.edu

Specialty section

This article was submitted to

Astrobiology,

a section of the journal

Frontiers in Astronomy and Space

Sciences

Received: 05 October 2021 Accepted: 09 November 2021

Published: 10 December 2021

Citation:

Irons MA and Irons LG (2021) Terraform Sustainability Assessment Framework for Bioregenerative Life

Support Systems.

Front. Astron. Space Sci. 8:789563. doi: 10.3389/fspas.2021.789563
In this perspective paper, we raise attention to the lack of methods or data to measure claims of sustainability for bioregenerative life support system designs and propose a method for quantifying sustainability. Even though sustainability is used as a critical mission criterion for deep space exploration, there result is a lack of coherence in the literature with the use of the word sustainability and the application of the criterion. We review a Generalized Resilient Design Framework for quantifying the engineered resilience of any environmental control and life support system and explain how it carries assumptions that do not fit the assumptions of sustainability that come out of environmental science. We explain bioregenerative life support system sustainability in the context of seven theoretical frameworks: a planet with soil, biogeochemical cycles, and ecosystem services provided to humans; human consumption of natural resources as loads and disturbances; supply chains as extensions of natural resources engineering application of; forced and natural cycles; bioregenerative systems as fragmented ecosystems; ecosystems as a network of consumer-resource interactions with critical factors occurring at ecosystem control points; and stability of human consumer resources. We then explain the properties of environmental stability and propose a method of quantifying resistance and resilience that are impacted by disturbances, extend this method to quantifying consistence and persistence that are impacted by feedback from loads. Finally, we propose a Terraform Sustainability Assessment Framework for normalizing the quantified sustainability properties of a bioregenerative life support system using the Earth model to control for variance.

Keywords: sustainability, resilience, bioregenerative life support system, ECLSS, space habitation, supply chain, fragmented ecosystem, terraform

\section{INTRODUCTION}

Across literature and popular science articles on bioregenerative life support systems (BLSSs), the word sustainable is commonly used as a critical mission criterion for deep space exploration (e.g., NASA 2012; Skibba 2018; Andrews 2019; NASA 2020; Kozyrovska et al., 2021; Maiwald et al., 2021). However, sustainability is not well-defined in the schema of BLSS. When the presentation and explanation of BLSS technologies that lay claim to sustainability are not accompanied by a discussion of parameters that would allow a measurement of sustainability, then such claims fall flat. The lack of supporting sustainability data is not surprising, considering that an understanding of sustainability is a relatively recent development among biological and environmental system researchers on Earth 
(e.g., Primmer and Furman 2012; Nimmo et al., 2015; Donohue et al., 2016; Pimm et al., 2019). The lack of coherence also could be a result of the BLSS concept growing out of the preceding development of non-biological, non-regenerative schema of the environmental control and life support system (ECLSS). ECLSS designs involve a system life cycle that depends upon the ability to maintain and repair the ECLSS during its useful life and then replace it with a new system at the end of its limited, useful life. Sustainable and limited are opposite outcomes.

Within the context of a limited, useful life, ECLSS developers still needed a way to measure the capability of an ECLSS to operate in the adverse conditions of space. The concept of system resilience has been defined in the field of risk analysis by Haimes (2009) as "the ability of the system to withstand a major disruption within an acceptable degradation of parameters and to recover within an acceptable time and composite costs and risks." The noted challenges in quantifying a measure of resilience are that 1) one must identify the multitude of disruption scenarios specific to the design of the system in question and necessarily apply a probabilistic scoring system to a limited set of classes of disruptions, and 2) given the inherent limited life of engineered systems, resilience will degrade over time, thus further constraining the time frame of scoring (Haimes 2009). The two challenges have been addressed specifically for ECLSSs using a Generalized Resilient Design Framework (GRDF) that limits disturbances to the failure of parts within the system; approximates all part failures to happen with equal, low probabilities; and considers such resilience only within a maximum, useful lifetime period during which the probability of any given part failing does not change (Matelli and Goebel 2018). The generalized resilient design framework for quantifying resilience can be applied to any ECLSS. We will refer to this as engineered resilience.

There is one fundamental difference between a BLSS and an ECLSS that makes engineered resilience insufficient to the task of defining the sustainability of a BLSS: the BLSS has one or more living biological components, whereas the ECLSS is fundamentally nonregenerative. An ECLSS has no inherent ability in its nature to maintain or repair itself. Even with human intervention in maintenance and repair of an ECLSS, the cost of such maintenance or repair eventually exceeds the cost of replacing the ECLSS entirely, thus reaching the end of its useful life. The bioregenerative nature of the biological components of a BLSS are specifically utilized to give the BLSS the ability to theoretically function indefinitely without replacement. BLSS system developers use the word sustainability in the same way environmental scientists use it because the BLSS is literally intended to be a living environment. The flip side of this coin is the potential for a $100 \%$ die off scenario in which the bioregenerative portion of both main lines and redundant lines fail in quick succession. The big difference between non-regenerative parts and bioregenerative elements is that failed non-regenerative parts can be replaced and systems returned to full function. Bioregenerative elements that fail $100 \%$ are at risk of quickly failing at $100 \%$ again due to undetected and unknown environmental conditions, such as the presence of an alien biological vector or mutated-Earth pathogen, which could require years to figure out and resolve. Space explorers do not have years to fix a down life support system. Sustainable BLSS designs must take this into consideration.

According to the Oxford English Dictionary (2004), environmentally sustainable is the "degree to which a process or enterprise is able to be maintained or continued while avoiding the long-term depletion of natural resources." Similarly, the United Nations Educational, Scientific and Cultural Organization (2017) defines sustainable engineering as the "process of using resources in a way that does not compromise the environment or deplete the materials for future generations." Four contextual elements are implied in these definitions, the first being that sustainment is endless, the second being that humans are being sustained, the third being that a natural environment is involved, and the fourth being that the functions of the natural environment have a critical, natural-resource basis. Different from engineered resilience, sustainability is a term that has arisen out of environmental science and natural resource management in the context of excessive human activities impacting our Earth ecological systems and environment (Du Pisani 2006). Instead of a probability that excessive human activity will result in adverse impacts to the environment, both the excessive human activity and the adverse impacts have been shown to exist. Environmental scientists look at whether ecological systems and the environment can continue to function in the presence of the excessive human activity. Additionally, environmental sustainability is not defined by the useful life of Earth's ecological systems and environment. A sustainable ecological system continues to support humans indefinitely under human activity. Thus, the assumptions that have been developed for a generalized resilient design framework to calculate engineered resilience of an ECLSS do not fit the assumptions of sustainability that come out of environmental science. In the context of environmental science, the sustainability of a BLSS is its capability to continue functioning indefinitely under nominal and potentially abnormal human activity in the course of expected and unplanned events. Any quantitative method of assessing sustainability must apply these assumptions. This is vital, considering environmental failure endangering human life is a very real risk for a spaceship or off-Earth colony.

In this perspective paper, we start by explaining the basis of BLSS sustainability in the context of the following theoretical frameworks: (2.1) a planetary (e.g. Earth): basis, in which biogeochemical cycles based in the soil are driven by planetary and solar forces out of which emerge environmental processes; (2.2) human consumption and disruption of natural resources and environmental processes acting as loads and disturbances that impact the entire system; (2.3) the human use of supply chains to artificially extend natural resources to anywhere they are needed, including space; (2.4) engineered elements of the BLSS working on a spectrum of forced and natural cycles; (2.5) bioregenerative elements of the BLSS functioning as fragmented ecosystems; (2.6) stability of the overall system being governed as critical factors identified by consumer-resource interactions disproportionately influencing the ecosystem at control points; and (2.7) sustainability of the BLSS and its ecosystem services 
network defined by stability of the human consumer resource(s) produced by the BLSS under human loads and impacted by disturbances. We then explain the properties of environmental stability, examine a method of quantifying resistance and resilience that are impacted by disturbances, extend this method to quantifying consistence and persistence that are impacted by feedback from loads, and propose a Sustainability Assessment Framework using the human consumer resources as the critical factors in these calculations. Finally, we propose a framework for normalizing the quantified sustainability properties of a BLSS using the Earth model to control for variance. The result is the Terraform Sustainability Assessment Framework, a method for quantifying the sustainability of a BLSS, and a framework that can be used to improve BLSS designs.

\section{THE ENVIRONMENTAL BASIS OF SUSTAINABILITY \\ 2.1 Soil, Biogeochemical Cycles, and Ecosystem Services}

Earth's human-sustaining environment is broadly the result of biogeochemical cycles (interactions of living things, minerals, and chemicals in cycles) that provide the essential elements required for interactions between the environment's biotic and abiotic components. Biogeochemical cycles are driven in complex ways by interactions in the soil, as the soil is where water, air, geological minerals, organic matter, microbes, plants, and other organisms interact chemically and physically, driven by solar, gravitational, and geo-thermal energy to produce the systems that make up the natural environment. When we refer to sustainability, we are referring to the fundamental ability of a soil-based biosphere to sustain humans. The implication is that, for a BLSS that utilizes biological functions to be sustainable and thus provide the necessary services required for human survival, the sustainability of those biological functions can only be based on the natural environment and the "root" soil basis from which the biological elements of the BLSS derive.

The Millennium Ecosystem Assessment (2003) proposed a framework to assess how the natural environment enables human life through ecosystem services - a framework now used by scientists, policymakers and government agencies around the world to assess resource use and conservation (Millennium Ecosystem Assessment 2005; Daily and Matson 2008; Fisher et al., 2009; Primmer and Furman 2012; FAO 2021). The framework proposed four categories of ecosystem services, starting with supporting services (e.g., biogeochemical cycles, biodiversity, soil formation, photosynthesis) that then support regulating services (e.g., biological control, carbon storage sequestration, air quality, climate regulation) that then regulate provisioning services that relate to human needs (e.g., clean air to breathe) and cultural services that relate to the development of society (e.g., education, recreation, custom, commerce, governance). Without the basis of supporting services, in which soil is a critical part, ecosystems would not exist. With an estimated $95 \%$ of the food consumed by humans being produced from the soil (FAO 2015), humans are dependent on the sustainability of a soil-basis for survival. Furthermore, ecological system theory defines the sustainability of Earth's biosphere in terms of the stability of natural cycles and processes under varying load feedbacks and disturbances (Benedetti-Cecchi 2003; García Molinos and Donohue 2011; Moreno-Mateos et al., 2017). To assess the sustainability of BLSS, we need to explore ecosystem stability in the context of a system sustaining humans (providing provisioning services) while experiencing loads and disturbances.

\subsection{Human Activity: Loads and Disturbances}

Just as provisioning services provided by Earth's environment are described in terms of human needs, loads on provisioning services are specific to human activities. All other activities that naturally occur within the environment (e.g., animals feeding on plants and on other animals), are part of the environment and are not considered to be loads in the context of sustainability. Human activities include not just the loads of the humans themselves (e.g., eating food and breathing) but also the loads of the infrastructure and industry that humans build and operate (e.g., urbanization, intensive agriculture, and the resulting increase in greenhouse gas emissions that load the Earth biosphere and contribute to climate change). Infrastructure and industry are built up and expanded using supply chains. Supply chains act as artificial extensions of provisioning services to multiply the use of consumable resources and extend the use of the resources to humans in locations where the resources would not naturally be available. Thus, supply chains must then be considered as both part of the environmental processes and part of the loads in the determination of sustainability of the environment.

In ecology, a disturbance is any event "that disrupts the structure of an ecosystem, community, or population, and changes resource availability or the physical environment" (White and Pickett 1985). Disturbances can act on any parts of a system's natural cycles (e.g., Müller et al., 2002; Tylianakis et al., 2008; Jentsch and White 2019) and its supply chains (e.g., Davis 1993; Christopher and Lee 2004; Bhatnagar and Sohal 2005; Hobbs 2020), not just the points of the natural cycles and supply chains where human consumption normally occurs. Disruptions can greatly reduce or eliminate the availability of provisioning services and the resources they provide. As artificial extensions of provisioning services and resources, supply chains introduce additional potential types and points of disturbances.

\subsection{Supply Chain Sustainability}

Supply chain sustainability to load and disturbance is built upon performance factors affecting, for example, a supply chain's production flexibility, lead time, demand variability response, inventory, and overall product and service quality (Davis 1993; Levy 1995; Bhatnagar and Sohal 2005; Sreedevi and Saranga 2017). Location-specific factors include access to resources, cost, infrastructure, and geographic distance to the endcustomer (Levy 1995; Bhatnagar and Sohal 2005). Relational factors are the various activities along the value chain of a product or service and the associated costs to link each into the supply chain (Levy 1995). Supply chain performance analysis has shown that the greater the quantity of performance factors, the more susceptible the supply chain is to natural disturbances such as weather events, and human disturbances such as distorted 
information, border closings, strikes, and socioeconomic fluctuations (e.g., Lee et al., 1997; Kleindorfer and Saad 2005; FAO et al., 2020; Hobbs 2020). Thus, supply chains with long paths and the need to reduce lead times commonly have increased risk of disturbance to meeting supply, process, and demand. With a smaller margin of error, the cost to maintain or recover efficiency in the short term increases and sustainability degrades in the long term.

The 2020 COVID-19 Pandemic almost immediately revealed how unstable our long-but-efficient supply chains are to sudden disturbances. The uncharacteristic freezing temperatures in Texas in 2021 also revealed how even localized supply chains (e.g., Texas electric grid) with minimal relational factors and shorter geographical distances can be disrupted by disturbances. The Texas cold wave of 2021 also demonstrated the catastrophic levels of failure that result when risk mitigation steps and adaptive management plans are not in place to recover or create predisturbance sustainability in supply chains (Blackmon 2021; Calma 2021; Krauss et al., 2021).

Engineered life support systems derive their sustainability from long, artificial supply chains that extend across Earth and out into space as the systems rely on resupply from the provisioning services of Earth to maintain operation (e.g., the ISS). An alternative to using Earth as a basis for sustainability that we will mention here (but leave detailed discussion to another paper) is to use another planetary body, such as Mars, as a basis (e.g., Kading and Straub 2015; Irons 2018; Berliner et al., 2021). For example, Irons (2018) proposes a "quasi-closed agroecological system" that utilizes ecological buffer zones, in situ resources, and ecosystem service reservoirs to establish natural cycles independent of supply chains from Earth.

\subsection{Engineered vs. Bioregenerative Resilience (Revisited From Introduction)}

It is noteworthy to consider the assumption that BLSS is inherently more sustainable than ECLSS due to the presence of bioregenerative components. For any given functional objective and the best available ECLSS and BLSS technologies that can be selected to meet the objective, sustainability will be affected by the engineered resilience of the non-regenerative parts of the system (Haimes 2009; Matelli and Goebel 2018) and the particular supply chains needed for the given technology to provision maintenance materials, repair parts, and consumable materials. The expectation is that sustainability is heavily weighted by both ECLSS/BLSS design and supply chain performance under load, and the risk mitigations, and adaptive management plans prepared for the common and unique disturbance points.

A theoretical advantage in sustainability of a BLSS over an ECLSS emerges as internal, non-regenerative components of the design of a BLSS are replaced with bioregenerative components, eliminating potential non-regenerative part failure points and reducing the need for supply chains for replacement parts. A theoretical advantage in sustainability of a BLSS over an ECLSS also emerges when the bioregenerative function is applied in a natural cycle that is more adaptive to loads and disturbances, rather than a forced cycle that has fixed steady state modes that are non-adaptive (Figure 1). When operated closer to a natural cycle, the implication is that it becomes more dependent on local, naturally renewable resources and buffering capacities and less dependent on supply chains, making it more adaptable to recovery from unplanned disruptive events (Irons 2018). Based upon this implication, operating a BLSS within a natural cycle with few or no supply chains would make it inherently more sustainable.

\subsection{Fragmented Ecosystems}

An area of research and ecosystem management here on Earth that is highly relevant to the question of sustainability of a BLSS is that of fragmented ecosystems. Fragmented ecosystems, such as isolated forests resulting from clear-cutting practices and segmented agricultural fields, experience constant edge effects such as wind, temperature fluctuations, and pest disturbances, that negatively affect the populations and communities that are openly exposed to those elements. The stability and quality of such systems is constantly under threat of habitat degradation, loss of connectivity to biogeochemical cycle inputs and outputs, and the loss of biodiversity and genetic movement through the system (Fahrig 2003; Hanski 2011; Wilson et al., 2016). A BLSS operated with need for a supply chain from Earth is effectively a fragmented ecosystem, considering the biological elements within the engineered system will have a large "edge" comprised of the supply chain between it and the Earth-basis ecosystem from which is derived the resources needed by the BLSS.

One example of a BLSS that could require a supply chain is a hydroponics system. In addition to the edge effect of the supply chain, hydroponics systems create edge environments along plant roots that would have otherwise been protected and buffered by a natural soil environment microbiome on Earth. An edge effect the plant may experience is exposure to pathogens that would have otherwise been kept at bay by a soil's microbiome. A field-based agricultural system in an artificial habitation module, even if it uses natural Earth soil, will also have an edge where plantings end along the engineered boundary and would have a separate edge associated with a supply chain if fertilizer additions are required to support the load of crop production. Edge environments are more susceptible to disturbances and load feedbacks and can be a place to measure the most critical factors that will limit the sustainability of a BLSS.

\subsection{Ecosystem Stability and Control Points}

Maintaining a human presence in space over the long-term using BLSS implies the system must have stability under nominal and potentially abnormal load conditions, as well as both expected and unplanned disturbance events. Stability of forced cycle engineered systems has commonly been defined as an asymptotic measure of whether a system maintains an equilibrium state under load and how quickly it returns to its equilibrium state following a disturbance or shock event (Holling 1996). However, the goal of a BLSS is to support or produce a natural cycle. Stability of natural-cycle systems over a long term will not necessarily be restricted and asymptotic. In comparison, naturally cycling ecosystems are complex networks of individual 


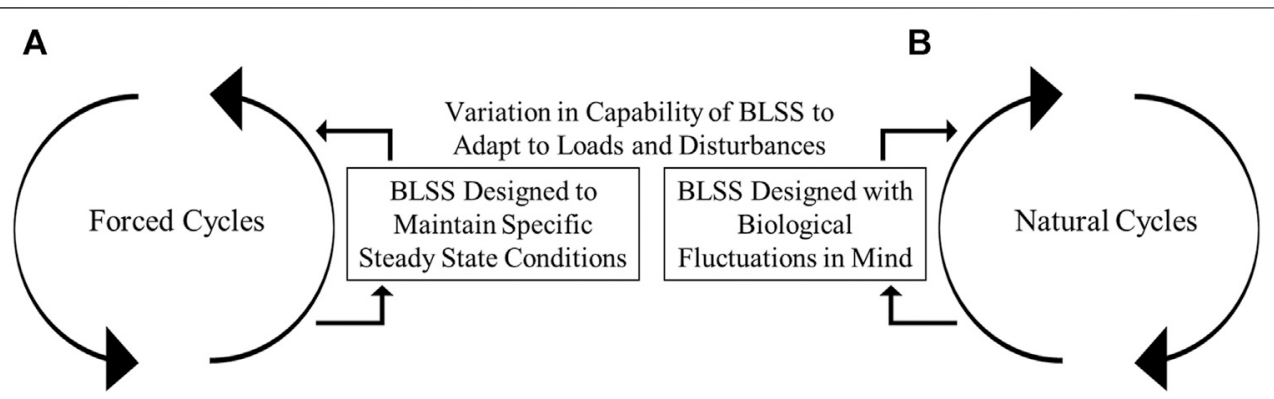

FIGURE 1 | Adaptability of bioregenerative life support systems (BLSS) in forced and natural cycles. (A) Approach in which a bioregenerative life support system is designed within engineered system processes and are expected to meet specific steady state parameters through forced cycle management. (B) Approach in which a bioregenerative life support system is designed within natural cycles with minimal to no forced cycle management.

species and groups of species that interact with the biotic and abiotic environment, creating unique and redundant functions and processes (Gray et al., 2021) made up of consumer-resource (i.e. producer) interactions that can vary over time and not necessarily around a mean (Benedetti-Cecchi 2003; Inouye 2005). Perturbations of varying magnitude, duration, and frequency over different spatial and temporal scales will elicit a range of responses that may affect the ecosystem immediately or may have long term effects that are not measurable on small time scales (Sousa 1984; Müller et al., 2002; Tylianakis et al., 2008; Pincebourde et al., 2012; Donohue et al., 2016; Jentsch and White 2019).

Considering the variance of the large number of consumerresource interactions comprising the complex network of an ecosystem, quantifying stability as a binary measure of single dimension (i.e., output is nominal or off-nominal) as is done with forced-cycle engineered systems is inaccurate and non-predictive for measuring the sustainability of a natural cycle system and can lead to ineffective management (Donohue et al., 2016; Pimm et al., 2019). The marine resources industry is a key example of how management of marine ecosystems is shifting away from focusing on single species stability and single ecosystem service management to ecosystem-based management-a management strategy that incorporates all ecosystem interactions, including those of humans, into the research and adaptive management of the system (Pikitch et al., 2004; Tam et al., 2017). The multidimensional approach of such a management strategy should be applied to assessing the stability of a BLSS. However, the large number of potential factors represented by all the consumerresource, send-receive, force-action interactions that make up the operation of a BLSS can be daunting. An approach is needed to select a subset of critical factors out of all interactions.

Ecosystem control points provide such an approach. In Bernhardt et al. (2017), ecosystem control points are defined as "areas of the landscape that exert disproportionate influence on the biogeochemical behavior of the ecosystem under study." For soil, these ecosystem control points are places where the movement of water and gases result in the transport, accumulation and export, and delivery of reactants to support permanent and activated biogeochemical activity. The concept of ecosystem control points can be applied to the process of an ecosystem service being delivered to humans by an Earth biogeochemical soil basis, a network of supply chains, and a BLSS comprised of non-regenerative parts combined with bioregenerative elements. One identifies the ecosystem control pointsto select a subset of all interactions and factors. This requires a careful analysis to identify the measurable, disproportionately influencing factors of the biogeochemical cycles and environmental processes, supply chains, nonregenerative subsystems of the BLSS, and bioregenerative subsystems of the BLSS. These disproportionately influencing factors are called critical factors.

Finally, the myriad possible ways that a system can be impacted by load feedbacks and disturbances necessitates limiting them to classes of load feedbacks and disturbances (Haimes 2009). For the BLSS schema, we recommend the following classes: non-regenerative part failure, biotic feed stock loss, pathogen and toxin introduction, mutation of biotic elements, unplanned load/leak, bioregenerative overgrowth. Classes of load feedbacks and disturbances for the ecosystem services on Earth and the associated supply chains that support the BLSS from Earth should also be utilized in the analysis. The BLSS development team should include biologists, environmental scientists, and supply chain experts to help with this analysis.

\subsection{Sustainability of Life Support Systems in Space}

To meet the mission criterion for a sustainable human presence in space, engineered life support systems tend to be defined by six functional objectives: 1) maintain closed-loop atmospheric pressure and composition within optimal parameters, 2) manage closed-loop water cycling, storage, and wastewater; 3 ) produce and store food to meet crew caloric and nutrition needs, 4) manage and recycle waste, 5) generate efficient energy for the system, and 6) ensure crew safety (e.g., Eckart 1996; NASA 2017). Table 1 shows how these six functional objectives are supported by the ecosystem services network (i.e., Earth environment basis of natural cycles and the ecological services provided by such cycles, and the supply chains that extend the resulting provisioning services to the location of humans in space) and 
TABLE 1 | Life support system functional objectives in the context of natural and forced cycle lead services and human loads.

Natural cycle lead (Earth Basis)
Forced cycle lead

$\begin{array}{llll}\text { Supply } & \text { ECLSS } & & \text { BLSS } \\ \text { chain } & \text { or BLSS } & & \end{array}$

$\rightarrow \quad$ Maintain atmospheric

evapotranspiration,

biological control, carbon

storage/sequestration

(soil), air quality regulation,

climate regulation

Water cycle, soil

creation,

photosynthesis,

biodiversity, habitat

Biogeochemical

cycles, nutrient

cycling,

photosynthesis,

biodiversity, habitat

Nutrient cycling,

biogeochemical

cycles, soil formation,

microbial primary

productivity

Depending on energy Depending on energy

source-water

cycling, sunlight source: water regulation,

climate regulation regulation and purification, soil formation; primary

productivity, air quality

Polation

regulation, water regulation

and purification, biological

control, erosion control,

atmospheric regulation,

disease regulation

Decomposition, carbon

storage, climate regulation,

water regulation, biological

control, atmospherics

All

\section{Provisioning}

Clean air to breath

Clean air to breath

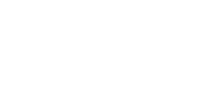

Clean water for

drinking and personal

hygiene

Biodiversity to

agricultural system

Waste recycling

Sunlight, wind,

flowing water,

gravitational potential

energy, biomass,

other

Raw materials and biodiversity for

adaptation, human

health and

adaptability to known

and unknown

disturbances composition

\begin{tabular}{|c|c|c|c|c|}
\hline$\rightarrow$ & $\begin{array}{l}\text { Maintain atmospheric } \\
\text { composition }\end{array}$ & $\begin{array}{l}\text { Maintain closed- } \\
\text { loop } \\
\text { atmospheric } \\
\text { pressure and } \\
\text { composition }\end{array}$ & $\begin{array}{l}\text { Absorbs O2 } \\
\text { Produces: } \\
\text { CO2, VOCs, } \\
\text { Airborne } \\
\text { particulate }\end{array}$ & $\begin{array}{l}\text { Absorbs } \mathrm{O} 2 \\
\text { Produces: CO2, } \\
\text { VOCs, Airborne } \\
\text { particulate }\end{array}$ \\
\hline$\rightarrow$ & $\begin{array}{l}\text { Manage water cycling } \\
\text { and storage }\end{array}$ & $\begin{array}{l}\text { Manage closed- } \\
\text { loop water } \\
\text { cycling, storage, } \\
\text { and wastewater }\end{array}$ & $\begin{array}{l}\text { Uses water } \\
\text { Produces } \\
\text { gray water } \\
\text { Produces } \\
\text { black water }\end{array}$ & $\begin{array}{l}\text { Uses water } \\
\text { Produces gray } \\
\text { water }\end{array}$ \\
\hline$\rightarrow$ & $\begin{array}{l}\text { Produce and store } \\
\text { food }\end{array}$ & $\begin{array}{l}\text { Produce and } \\
\text { store food to } \\
\text { meet crew } \\
\text { caloric and } \\
\text { nutrition needs }\end{array}$ & $\begin{array}{l}\text { Eats food } \\
\text { Produces } \\
\text { food waste }\end{array}$ & $\begin{array}{l}\text { Uses plant } \\
\text { material for spare } \\
\text { parts }\end{array}$ \\
\hline$\rightarrow$ & Manage waste & $\begin{array}{l}\text { Manage and } \\
\text { recycle waste }\end{array}$ & $\begin{array}{l}\text { Produces } \\
\text { trash }\end{array}$ & $\begin{array}{l}\text { Produces } \\
\text { industrial waste }\end{array}$ \\
\hline$\rightarrow$ & Generate energy & $\begin{array}{l}\text { Generate } \\
\text { efficient energy } \\
\text { for the system }\end{array}$ & $\begin{array}{l}\text { Consumes } \\
\text { energy } \\
\text { Produces } \\
\text { heat }\end{array}$ & $\begin{array}{l}\text { Consumes } \\
\text { energy } \\
\text { Produces heat }\end{array}$ \\
\hline$\rightarrow$ & $\begin{array}{l}\text { Produce spare parts } \\
\text { and consumables for } \\
\text { engineered systems } \\
\text { Safeguard against } \\
\text { known disturbances } \\
\text { - }\end{array}$ & $\begin{array}{l}\text { Ensure crew } \\
\text { safety }\end{array}$ & $\begin{array}{l}\text { Subject to } \\
\text { unplanned } \\
\text { events }\end{array}$ & $\begin{array}{l}\text { Consumes } \\
\text { material } \\
\text { Produces material } \\
\text { waste } \\
\text { Produces } \\
\text { additional } \\
\text { hazards for } \\
\text { humans }\end{array}$ \\
\hline
\end{tabular}

Loads

\section{functiona}

objectives

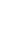

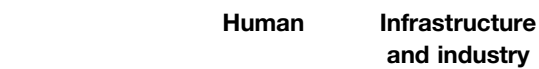

humans the ECLSS or BLSS that convert the provisioned resources provided by the supply chain into the resources that meet human consumer need. Table 1 also identifies the human loads and space-based infrastructure and industry loads that impact the sustainability of the whole system.

These load points are the final consumer-resource interactions in the complex network that make up the BLSS and its connection back to Earth and the soil basis. As such, the measures of resources directly consumed by humans are the dependent variable critical factors (DVCFs) of the independent variable critical factors (IVCFs) measured at the control points. The IVCFs can be impacted by feedbacks of the human loads (i.e., IVCFs pulled out of nominal by human load rates) and by disturbances (i.e. expected and unplanned events). Thus, the stability of the BLSS is dependent upon the stability of the human resource DVCF when the IVCFs are impacted. We define the sustainability of a BLSS to be the stability of the human resource DVCF produced by a BLSS in response to human load and disruption impacts on IVCFs at the environmental control points of the BLSS and its ecosystem services network. We apply this definition in our development of a Terraform Sustainability Assessment Framework.

\section{TERRAFORM SUSTAINABILITY ASSESSMENT FRAMEWORK}

\subsection{Quantifying Sustainability}

Studies to assess the stability of ecosystem critical factors have used variability, persistence, resistance, and resilience as properties of ecological stability (Pimm 1984). Where the challenge lies in quantifying these stability properties is a lack of clear definitions of the terms and a lack in understanding of how to capture the complexity and variety of ecosystem responses to disturbances (Donohue et al., 2016; Pimm et al., 2019). 
Nimmo et al. (2015) proposes quantifying resistance and resilience as

$$
\begin{gathered}
R s=X 2 / X 1 \\
R l=X 3 / X 1-R s
\end{gathered}
$$

Resistance (Rs) is the ratio of the minimum level to which a critical factor $(X)$ drops due to a disturbance $(X 2)$ to its value prior to disturbance $(X 1)$, and defined as "the ability to maintain functional output immediately following a disturbance." Resilience $(R l)$ is the difference of the resistance ratio $(R s)$ and the ratio of the value to which the critical factor recovers following the drop $(X 3)$ to its value prior to disturbance $(X 1)$, defined as "the ability to return to functional output after a disturbance has passed." Resistance and resilience, as described here, are the stability properties associated with disturbances.

As resistance and resilience relate to disturbances, variability and persistence relate to load feedback processes. However, whereas variability is defined as how much a critical factor drops as a result of feedback from a load, we propose to use what we call consistence that we define as "the ability to maintain functional output immediately upon establishment of a load." Persistence is "the ability to return to functional output while loading is ongoing." Equations for consistence and persistence would then follow the same model as resistance and resilience

$$
\begin{gathered}
C=Y 2 / Y 1 \\
P=Y 3 / Y 1-C
\end{gathered}
$$

where consistence $(C)$ is the ratio of the minimum level to which a critical factor $(Y)$ drops under load feedback $(Y 2)$ to its value prior to loading $(Y 1)$, and persistence $(P)$ is the difference of the consistence ratio $(C)$ and the ratio of the value to which the critical factor recovers following the drop while still under load $(Y 3)$ to its value prior to loading $(Y 1)$. For clarification, symbols " $\mathrm{X}$ " and " $\mathrm{Y}$ " are used to differentiate disturbance critical factors $(X)$ and load feedback critical factors $(Y)$. It is worth noting that a given critical factor could be impacted by both disturbances and load feedbacks.

When $X$ and $Y$ are selected to be the same human resource DVCF of a BLSS, the stability properties represent measures of sustainability for the BLSS, as we defined in subsection 2.7. Ecosystem control points and the associated IVCFs for the given BLSS and its classes of disturbances and load feedbacks must be selected to meet five caveats identified by Nimmo et al. (2015) for use of these equations. The theories and methods discussed in section 2 enable the BLSS developer to meet the caveats. With these theories and methods, BLSS developers can perform analyses to predict how feedbacks from human loads and impacts from disturbances uniquely and commonly affect IVCFs. BLSS developers can then perform computer simulations and physical tests to see how the classes of selected load feedbacks and disturbances affect any given IVCF (while controlling for the other IVCFs), and how the affected IVCF impacts the particular human resource DVCF produced by the BLSS. Values of the human resource DVCF prior to disturbance/loading (X1/Y1), immediately following disturbance/loading (X2/Y2), and at a later time following disturbance/loading (X3/Y3) are then used to calculate resistance, resilience, consistence, and persistence. Using this
Sustainability Assessment Framework, values of these four properties of sustainability can be calculated for the worst-case scenario of each class of disturbance and load feedback for each BLSS.

\subsection{Normalizing to Terraform Specific Stabilities}

The Sustainability Assessment Framework we have provided thus far quantifies sustainability of a BLSS as a measure of four properties of stability of human resource DVCFs; however, we still have not accounted for the effect of variance of consumer-resource interactions on the measurements of critical factors. We next propose a Terraform Sustainability Assessment Framework to account for the effect of variance on an assessment of BLSS stability by comparing the four stability properties we can calculate for a BLSS to those of a functionally equivalent Earth environment model under proportional load and disturbance effects. We are controlling the effect of variance on the sustainability calculations of a BLSS by normalizing the stability properties to those of an equivalent (in bioregenerative aspects) Earth environment that would also be affected by variance. Any influence of variance on the $X 3$ and $Y 3$ critical factors of Equations 2, 4, respectively, would be assumed to be in play in both the BLSS and Earth model environment(s), and thus, their influence on the calculations is controlled for in the normalization. The results are four new terms that we call terraform specific stabilities: terraform specific resistance $\left(R s_{T}\right)$, terraform specific resilience $\left(R l_{T}\right)$, terraform specific consistence $\left(C_{T}\right)$, and terraform specific persistence $\left(P_{T}\right)$.

$$
\begin{aligned}
R s_{T} & =R s_{B L S S} / R s_{E} \\
R l_{T} & =R l_{B L S S} / R l_{E} \\
C_{T} & =C_{B L S S} / C_{E} \\
P_{T} & =P_{B L S S} / P_{E}
\end{aligned}
$$

where each normalization is the ratio of the value of a BLSS stability property (e.g., $R s_{B L S S}$ ) to the stability property of the proportional Earth model (e.g., $R s_{E}$ ). We use the word terraform for the normalized properties considering the calculations are developed on the basis of Earth sustainability; thus, any BLSS that achieves terraform specific stabilities of 1 has effectively terraformed the human habitation supported by the BLSS, making it as sustainable as an equivalent system on Earth.

\subsection{Designing for Sustainability}

Finally, we recommend a formalized and adaptable approach (Figure 2) to using the Terraform Sustainability Assessment Framework for BLSS system developers to assess and quantify sustainability. The assessment can be performed on a BLSS design at any phase of development as a tool for iterative improvement of the design and associated risk and adaptive management plans. Development teams should be staffed with engineers, supply chain experts, environmental scientists, ecologists, and science specialists (e.g., soil scientists) to ensure valid application of the theories we utilized to develop this framework.

By defining terraform specific stability properties of BLSSs on the basis of proportional Earth models, we provide a tool to assist 


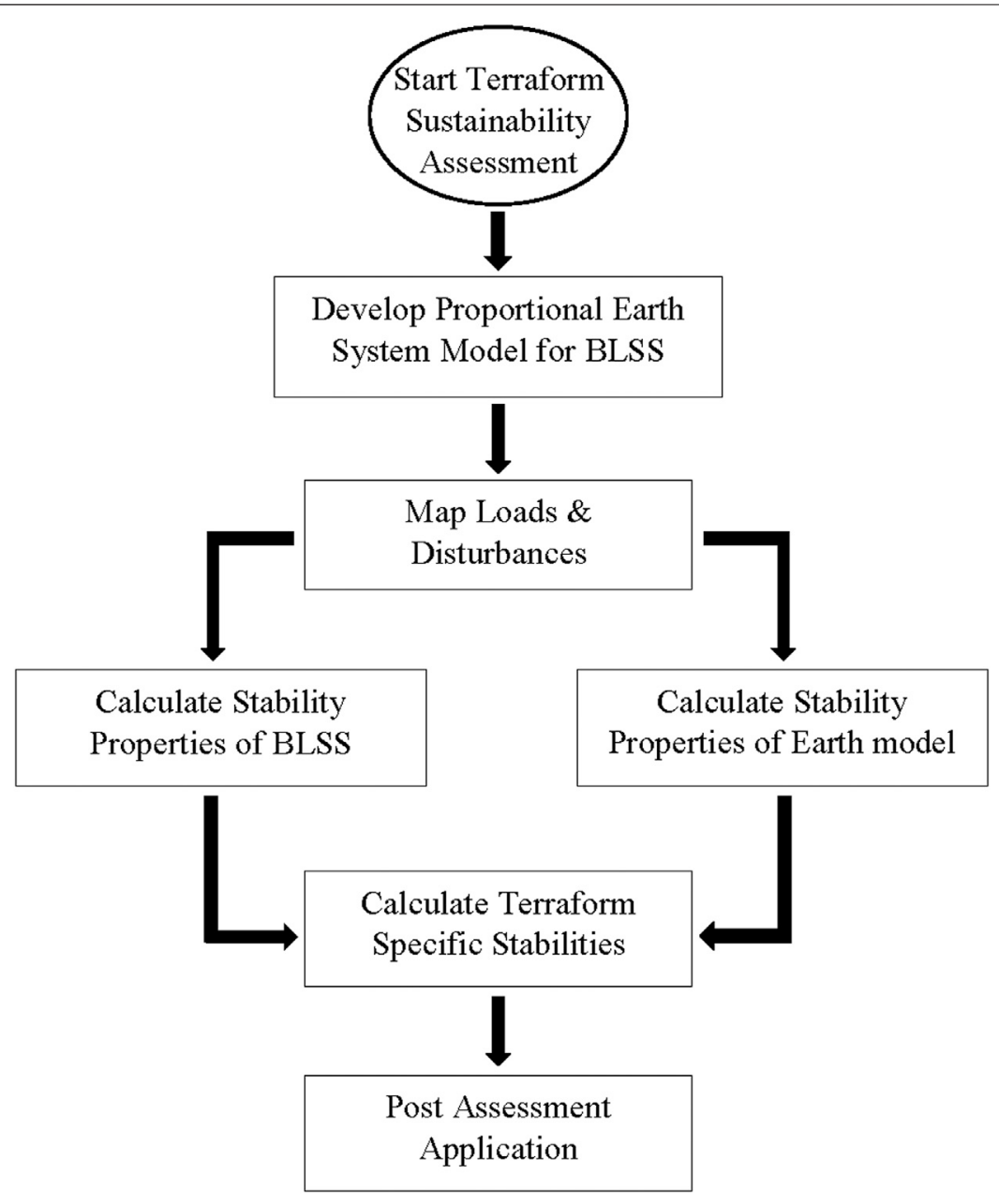

FIGURE 2 | Proposed Terraform Sustainability Assessment Framework process flow.

in the purposeful advancement of BLSS designs towards the ideal of no longer requiring Earth supply chains. Our hope is that previously unknown questions and development challenges will be discovered in the process of analyzing and managing the sustainability of any given BLSS using this framework. We encourage the development of case studies of BLSS designs using our proposed Terraform Sustainability Assessment Framework. Such case studies will not only help with the development of more sustainable life support for space but also the development of technologies that can be used for sustainable practices on Earth.

\section{CONCLUSION}

Terraforming has always been a concept in the realm of science fiction. However, it is an idea that has its roots in the science of Earth biogeochemistry, soil formation, and ecological system succession. By modeling the BLSS as an extension of the ecosystem services provided to humans on Earth and then applying theoretical developments of environmental science, we have provided a definition of sustainability of a BLSS and a framework for quantifying it, normalizing it, and applying it to design. Use of this framework will now provide research and development teams and program managers with a way to assess claims of sustainability of BLSS technologies. It also provides a tool for ongoing improvement of BLSS designs, making them more bioregenerative and more naturally cycling, as well as development of system complexes of BLSS systems (terraform life support systems-TFLSS) that will provide all human consumption resources for space explorers of the future. The ultimate objective is to move the science and engineering toward local, scalable terraforming on other planets. To support this endeavor, we see the need for new disciplines in astroecology, extraterrestrial biospherics, and terraform engineering. We encourage career researchers, early career scientists, and students to build on this perspective paper through multidisciplinary, collaborative research with the objective of building these new disciplines. 


\section{DATA AVAILABILITY STATEMENT}

The original contributions presented in the study are included in the article/Supplementary Material, further inquiries can be directed to the corresponding author.

\section{AUTHOR CONTRIBUTIONS}

All authors listed have made a substantial, direct, and intellectual contribution to the work and approved it for publication.

\section{FUNDING}

MI was supported by a National Science Foundation Graduate Research Fellowship. This material is based upon work supported by the National Science Foundation Graduate Research Fellowship Program under Grant No. DGE-1650441. Any

\section{REFERENCES}

Andrews, R. G. (2019). Can Spaceflight Save the Planet. Scientific American. Available at: https://www.scientificamerican.com/article/canspaceflight-save-the-planet/?fbclid=IwAR3KkEfpWsCkPrU_jiUHdFQTOciu6UluGMdKom0cWv8wdBUZDNxnL_rVA4.

Benedetti-Cecchi, L. (2003). The Importance of the Variance Around the Mean Effect Size of Ecological Processes. Ecology 84, 2335-2346. doi:10.1890/02-8011

Berliner, A. J., Hilzinger, J. M., Abel, A. J., McNulty, M. J., Makrygiorgos, G., Averesch, N. J. H., et al. (2021). Towards a Biomanufactory on Mars. Front. Astron. Space Sci. 8, 711550. doi:10.3389/fspas.2021.711550

Bernhardt, E. S., Blaszczak, J. R., Ficken, C. D., Fork, M. L., Kaiser, K. E., and Seybold, E. C. (2017). Control Points in Ecosystems: Moving beyond the Hot Spot Hot Moment Concept. Ecosystems 20, 665-682. doi:10.1007/s10021-0160103-y

Bhatnagar, R., and Sohal, A. (2005). Supply Chain Competitiveness: Measuring the Impact of Location Factors, Uncertainty and Manufacturing Practices. Technovation 25, 443-456. doi:10.1016/s0166-4972(03)00172-x

Blackmon, D. (2021). Texas Must Fix its Chronic Power Grid Resiliency Issues or Risk Becoming Another California. New York, New York: Forbes. Available at: https://www.forbes.com/sites/davidblackmon/2021/02/15/texas-must-fixits-chronic-power-grid-resiliency-issues-or-risk-becoming-anothercalifornia/?sh=7344ef45279c.

Calma, J. (2021). Texas Has Work to Do to Avoid Another Energy Crisis. New York, New York: The Verge. Available at: https://www.theverge.com/2021/2/17/ 22288292/texas-grid-upgrade-disaster-planning-power-outage-energy-crisis.

Christopher, M., and Lee, H. (2004). Mitigating Supply Chain Risk through Improved Confidence. Int. Jnl Phys. Dist Log Manage. 34, 388-396. doi:10.1108/09600030410545436

Daily, G. C., and Matson, P. A. (2008). From Theory to Implementation. Proc. Natl. Acad. Sci. 105 (28), 9455-9456. doi:10.1073/pnas.0804960105

Davis, T. (1993). Effective Supply Chain Management. Sloan Manag. Rev. 34, 35-46.

Donohue, I., Hillebrand, H., Montoya, J. M., Petchey, O. L., Pimm, S. L., Fowler, M. S., et al. (2016). Navigating the Complexity of Ecological Stability. Ecol. Lett. 19, 1172-1185. doi:10.1111/ele.12648

Du Pisani, J. A. (2006). Sustainable Development - Historical Roots of the Concept. Environ. Sci. 3 (2), 83-96. doi:10.1080/15693430600688831

Eckart, P. (1996). "Physico-Chemical versus Bioregenerative Life Support," in Spaceflight Life Support and Biospherics. Editors L. Markley, W. L. Larson, R. E. Münch, and J. F. Shea (Torrance, CA: Microcosm, Inc.), 125-174. opinions, findings, and conclusions or recommendations expressed in this material are those of the authors and do not necessarily reflect the views of the National Science Foundation. The publication fee was covered through a fellowship held by MI by Norfolk Institute, a non-profit organization that supports research in human resilience.

\section{ACKNOWLEDGMENTS}

We thank Johannes Lehmann (Cornell University) for providing advisement and discussion. We thank colleagues in the Lehmann Lab at Cornell University for useful discussions on the subject matter. We thank Jim Heffernan (Duke University), Justin Wright (Duke University), and Daniel Richter (Duke University) for early advisement on applying environmental and ecological sciences to space environments. We thank the National Science Foundation for providing funding through its Graduate Research Fellowship Program.

Fahrig, L. (2003). Effects of Habitat Fragmentation on Biodiversity. Annu. Rev. Ecol. Evol. Syst. 34, 487-515. doi:10.1146/annurev.ecolsys. 34.011802 .132419

FAO (2021). Ecosystem Services \& Biodiversity (ESB). Available at: http://www.fao. org/ecosystem-services-biodiversity/en/.

FAO (2015). Healthy Soils Are the Basis for Healthy Food Production. Available at: http://www.fao.org/soils-2015/news/news-detail/en/c/277682/.

FAO, IFAD, UNICEF, WFP and WHO (2020). "What Is Driving the Cost of Nutritious Foods," in The State of Food Security and Nutrition in the World 2020: Transforming Food Systems for Affordable Healthy Diets (Rome: FAO), 115-138.

Fisher, B., Turner, R. K., and Morling, P. (2009). Defining and Classifying Ecosystem Services for Decision Making. Ecol. Econ. 68 (3), 643-653. doi:10.1016/j.ecolecon.2008.09.014

García Molinos, J., and Donohue, I. (2011). Temporal Variability within Disturbance Events Regulates Their Effects on Natural Communities. Oecologia 166, 795-806. doi:10.1007/s00442-011-1923-2

Gray, C., Ma, A., McLaughlin, O., Petit, S., Woodward, G., and Bohan, D. A. (2021). Ecological Plasticity Governs Ecosystem Services in Multilayer Networks. Commun. Biol. 4, 1-7. doi:10.1038/s42003-020-01547-3

Haimes, Y. Y. (2009). On the Definition of Resilience in Systems. Risk Anal. 29 (4), 498-501. doi:10.1111/j.1539-6924.2009.01216.x

Hanski, I. (2011). Habitat Loss, the Dynamics of Biodiversity, and a Perspective on Conservation. AMBIO 40, 248-255. doi:10.1007/s13280-011-0147-3

Hobbs, J. E. (2020). Food Supply Chains during the COVID-19 Pandemic. Can. J. Agric. Economics/Revue canadienne d'agroeconomie 68, 171-176. doi:10.1111/cjag.12237

Holling, C. S. (1996). "Engineering Resilience versus Ecological Resilience," in Engineering within Ecological Constraints. Editor P. E. Schulze (Washington D.C.: National Academy Press), 31-43.

Inouye, B. D. (2005). The Importance of the Variance Around the Mean Effect Size of Ecological Processes: Comment. Ecology 86 (1), 262-265. doi:10.1890/033180

Irons, M. A. (2018). "Ecological System Model for a Self-Sustaining and Resilient Human Habitation on the Moon and Mars and for Food Security and Climate Change Mitigation Anywhere on Earth,". U.S. Patent No 9,970,208 (Washington, D.C: U.S. Patent and Trademark Office).

Jentsch, A., and White, P. (2019). A Theory of Pulse Dynamics and Disturbance in Ecology. Ecology 100, 1-15. doi:10.1002/ecy.2734

Kading, B., and Straub, J. (2015). Utilizing In-Situ Resources and 3D Printing Structures for a Manned Mars mission. Acta Astronautica 107, 317-326. doi:10.1016/j.actaastro.2014.11.036 
Kleindorfer, P. R., and Saad, G. H. (2005). Managing Disruption Risks in Supply Chains. Prod. Operations Manag. 14, 53-68. doi:10.1111/j.19375956.2005.tb00009.x

Kozyrovska, N., Reva, O., Podolich, O., Kukharenko, O., Orlovska, I., Terzova, V., et al. (2021). To Other Planets with Upgraded Millennial Kombucha in Rhythms of Sustainability and Health Support. Front. Astron. Space Sci. 8, 701158. doi:10.3389/fspas.2021.701158

Krauss, C., Fernandez, M., Penn, I., and Rojas, R. (2021). How Texas' Drive for Energy Independence Set it up for Disaster. New York, New York: The New York Times. ISSN 0362-4331. Available at: https://www.nytimes.com/2021/02/21/us/ texas-electricity-ercot-blackouts.html.

Lee, H. L., Padmanabhan, V., and Whang, S. (1997). The Bullwhip Effect in Supply Chains. Sloan Manag. Rev. 38, 93-102.

Levy, D. L. (1995). International Sourcing and Supply Chain Stability. J. Int. Bus Stud. 26, 343-360. doi:10.1057/palgrave.jibs.8490177

Maiwald, V., Schubert, D., Quantius, D., and Zabel, P. (2021). From Space Back to Earth: Supporting Sustainable Development with Spaceflight Technologies. Sustain. Earth 4, 1-16. doi:10.1186/s42055-021-00042-9

Matelli, J. A., and Goebel, K. (2018). Resilience Evaluation of the Environmental Control and Life Support System of a Spacecraft for Deep Space Travel. Acta Astronautica 152, 360-369. doi:10.1016/j.actaastro.2018.08.045

Millennium Ecosystem Assessment (2003). "Ecosystems and Their Services," in Ecosystems and Human Well-Being: A Framework for Assessment (Washington D.C.: Island Press), 49-62.

Millennium Ecosystem Assessment (2005). "How Have Ecosystem Services and Their Uses Changed," in Ecosystems and Human Well-Being: Synthesis (Washington D.C.: Island Press), 39-48.

Moreno-Mateos, D., Barbier, E. B., Jones, P. C., Jones, H. P., Aronson, J., LópezLópez, J. A., et al. (2017). Anthropogenic Ecosystem Disturbance and the Recovery Debt. Nat. Commun. 8, 1-6. doi:10.1038/ncomms14163

Müller, A. K., Westergaard, K., Christensen, S., and Sørensen, S. J. (2002). The Diversity and Function of Soil Microbial Communities Exposed to Different Disturbances. Microb. Ecol. 44, 49-58. doi:10.1007/s00248001-0042-8

NASA (2017). Life Support Systems: Sustaining Humans beyond Earth. Available at: https://www.nasa.gov/content/life-support-systems.

NASA (2020). NASA's Plan for Sustained Lunar Exploration and Development. Available at: https://www.nasa.gov/feature/nasa-outlines-lunar-surfacesustainability-concept.

NASA (2012). Voyages: Charting the Course for Sustainable Human Space Exploration. Available at: https://www.nasa.gov/exploration/whyweexplore/ voyages-report.html.

Nimmo, D. G., Mac Nally, R., Cunningham, S. C., Haslem, A., and Bennett, A. F. (2015). Vive la résistance: reviving resistance for 21st century conservation. Trends Ecol. Evol. 30, 516-523. doi:10.1016/j.tree.2015.07.008

Oxford English Dictionary (2004). "Environmentally Sustainable," in Oxford English Dictionary 2nd Ed (Oxford: Oxford University Press).

Pikitch, E. K., Santora, C., Babcock, E. A., Bakun, A., Bonfil, R., ConoverDayton, D. O. P., et al. (2004). Ecosystem-based Fishery Management. Science 305, 346-347. doi:10.1126/science.1098222

Pimm, S. L., Donohue, I., Montoya, J. M., and Loreau, M. (2019). Measuring Resilience Is Essential to Understand it. Nat. Sustain. 2, 895-897. doi:10.1038/ s41893-019-0399-7

Pimm, S. L. (1984). The Complexity and Stability of Ecosystems. Nature 307, 321-326. doi:10.1038/307321a0
Pincebourde, S., Sanford, E., Casas, J., and Helmuth, B. (2012). Temporal Coincidence of Environmental Stress Events Modulates Predation Rates. Ecol. Lett. 15, 680-688. doi:10.1111/j.1461-0248.2012.01785.x

Primmer, E., and Furman, E. (2012). Operationalising Ecosystem Service Approaches for Governance: Do Measuring, Mapping and Valuing Integrate Sector-specific Knowledge Systems. Ecosystem Serv. 1, 85-92. doi:10.1016/j.ecoser.2012.07.008

Skibba, R. (2018). Greening the Future of Outer Space: A Team of Scientists and Policy Experts Want to Develop Space Sustainably for Future Generations. Smithsonian Magazine. Available at: https://www.smithsonianmag.com/science-nature/ greening-future-outer-space-180969212/?fbclid=IwAR2gAO1hRW9aORAT dMv551WIO3XI0ym2xlGqORI21YxXC5VGMjiSFgea6SI.

Sousa, W. P. (1984). The Role of Disturbance in Natural Communities. Annu. Rev. Ecol. Syst. 15, 353-391. doi:10.1146/annurev.es.15.110184.002033

Sreedevi, R., and Saranga, H. (2017). Uncertainty and Supply Chain Risk: the Moderating Role of Supply Chain Flexibility in Risk Mitigation. Int. J. Prod. Econ. 193, 332-342. doi:10.1016/j.ijpe.2017.07.024

Tam, J. C., Link, J. S., Rossberg, A. G., Rogers, S. I., Levin, P. S., Rochet, M.-J., et al. (2017). Towards Ecosystem-Based Management: Identifying Operational Food-Web Indicators for marine Ecosystems. Int. Counc. Exploration Sea J. Mar. Sci. 74, 2040-2052. doi:10.1093/icesjms/fsw230

Tylianakis, J. M., Didham, R. K., Bascompte, J., and Wardle, D. A. (2008). Global Change and Species Interactions in Terrestrial Ecosystems. Ecol. Lett. 11, 1351-1363. doi:10.1111/j.1461-0248.2008.01250.x

United Nations Educational, Scientific and Cultural Organization (2017) Sustainable Engineering. Available at: http://www.unesco.org/new/en/ natural-sciences/science-technology/engineering/sustainable-engineering/.

White, P. S., and Pickett, S. T. A. (1985). "Natural Disturbance and Patch Dynamics: an Introduction," in The Ecology of Natural Disturbance and Patch Dynamics. Editors S. T. A. Pickett and P. S. White (New York, NY: Academic Press), 3-13. doi:10.1016/b978-0-08-050495-7.50006-5

Wilson, M. C., Chen, X.-Y., Corlett, R. T., Didham, R. K., Ding, P., Holt, R. D., et al. (20162016). Habitat Fragmentation and Biodiversity Conservation: Key Findings and Future Challenges. Landscape Ecol. 31, 219-227. doi:10.1007/ s10980-015-0312-3

Conflict of Interest: Author LI is on the Board of Directors of Norfolk Institute LLC which operates as a non-profit entity.

The authors declare that the research was conducted in the absence of any commercial or financial relationships that could be construed as a potential conflict of interest.

Publisher's Note: All claims expressed in this article are solely those of the authors and do not necessarily represent those of their affiliated organizations, or those of the publisher, the editors and the reviewers. Any product that may be evaluated in this article, or claim that may be made by its manufacturer, is not guaranteed or endorsed by the publisher.

Copyright $\odot 2021$ Irons and Irons. This is an open-access article distributed under the terms of the Creative Commons Attribution License (CC BY). The use, distribution or reproduction in other forums is permitted, provided the original author(s) and the copyright owner(s) are credited and that the original publication in this journal is cited, in accordance with accepted academic practice. No use, distribution or reproduction is permitted which does not comply with these terms. 